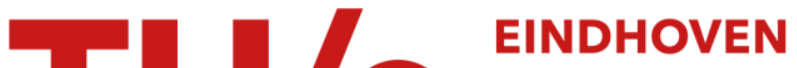 \\ UNIVERSITY OF \\ TECHNOLOGY
}

\section{Fuzzy control in a single-machine system}

Citation for published version (APA):

Wang, H. G., \& Rooda, J. E. (1996). Fuzzy control in a single-machine system. Production Planning \& Control, 7(6), 577-584.

Document status and date:

Published: 01/01/1996

\section{Document Version:}

Publisher's PDF, also known as Version of Record (includes final page, issue and volume numbers)

\section{Please check the document version of this publication:}

- A submitted manuscript is the version of the article upon submission and before peer-review. There can be important differences between the submitted version and the official published version of record. People interested in the research are advised to contact the author for the final version of the publication, or visit the $\mathrm{DOI}$ to the publisher's website.

- The final author version and the galley proof are versions of the publication after peer review.

- The final published version features the final layout of the paper including the volume, issue and page numbers.

Link to publication

\section{General rights}

Copyright and moral rights for the publications made accessible in the public portal are retained by the authors and/or other copyright owners and it is a condition of accessing publications that users recognise and abide by the legal requirements associated with these rights.

- Users may download and print one copy of any publication from the public portal for the purpose of private study or research.

- You may not further distribute the material or use it for any profit-making activity or commercial gain

- You may freely distribute the URL identifying the publication in the public portal.

If the publication is distributed under the terms of Article 25fa of the Dutch Copyright Act, indicated by the "Taverne" license above, please follow below link for the End User Agreement:

www.tue.nl/taverne

Take down policy

If you believe that this document breaches copyright please contact us at:

openaccess@tue.nl

providing details and we will investigate your claim. 


\title{
Fuzzy control in a single-machine system
}

\author{
'H. G. WANG and J. E. ROODA
}

Keywords fuzzy control, discrete event dynamic systems, single machine, characteristic curves

\begin{abstract}
As a new application area we have been tried to apply the fuzzy control concept in discrete event dynamic systems (DEDS) control problems. The fuzzy control of a single-machine system is presented. Simulation studies have been performed on the basis of a descriptive model for investigating the control performance. Two other control approaches, namely proportional control (P-control) and load-oriented order release control (LOOR-control), are employed to compare with the fuzzy control approach. It is concluded that fuzzy control is a practical and effective way to control DEDS. The fuzzy control module developed during this study can be easily adapted for fuzzy control of other DEDS, for example job-shop systems. This paper should be considered as the first step in using fuzzy control concept for the control of DEDS.
\end{abstract}

\section{Introduction}

Due to the increasing competition among companies and the fast development of computers, good automatic control of industrial systems has become important. Our interest is in the control of discrete industrial systems. Discrete industrial systems are DEDS which are characterized by the successive occurrence of discrete events, have inherent uncertainty, and are stochastic. The classical control approach is not applicable here because of the lack of mathematical model for such system.

Because many of the system parameters are described using a linguistic language instead of numerical values, like short lead time, high throughput, low work-in-process and so on, and because a lot of expert knowledge and operator experience of the control of such systems is available, fuzzy control might be a useful technique for the control of DEDS. Automatic control is possible if the aforementioned linguistic control knowledge or protocol can be transformed into a precise numerical calculus which can be recognized and used by a computer.

The fuzzy control concept is based on fuzzy set theory, which was introduced by Zadeh in 1965 (Zadeh 1965). This

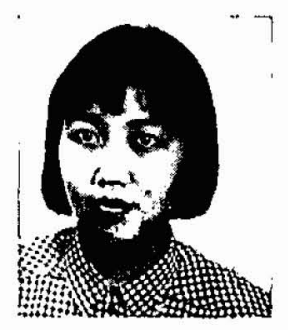

Authors: H. G. Wang and J. E. Rooda, Department of Mechanical Engineering, Eindhoven University of Technology, P.O. Box 513, 5600 MB Eindhoven, The Netherlands.

HoNG GUANG WANG graduated with a BSc in electrical engineering at Xi'an Jiaotong University (XJTU) in China in 1985. She obtained an MSc in electronic engineering at the same university in 1988. Since then she has been an assistant lecturer at $\mathrm{XJ} T U$. She is currently a $\mathrm{PhD}$ student in mechanical engineering at Eindhoven University of Technology with specialist subject the application of fuzzy control in DEDS.

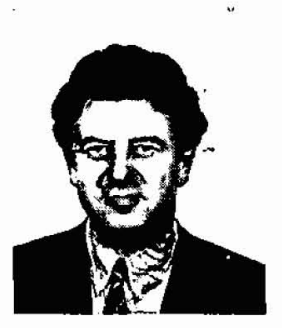

JACOBUS E. ROODA received an MSc degree in food technology from Wageningen Agricultural University in 1971. In 1978, he received a $\mathrm{PhD}$ degree in mechanical engineering from the University of Twente. Since 1985 he has been a professor of system engineering at Eindhoven University of Technology. His research interests include modelling of discrete-event and continuous-time systems, and the design of industrial systems. Professor Rooda is a member of IEEE, IFAC (Mantech), ACM, and WEHTB (West European Professors of Technology Management). 
theory was introduced to represent and to reason with fuzzy or linguistic concepts and is able to tackle several interrelated linguistic variables. It provides an effective way to model operators' or experts' controlling behaviour which may cnable a computer to perform control instead of human beings. Thus it might be a useful technique for DEDS control. Starting with a linguistic model of human beings' control behaviour rather than a precise mathematical model of the system itsclf is onc of the advantages of fuzzy control over classical (or conventional) control.

Fuzzy control concepts have been applied to a wide variety of systcms, especially continuous control systems (Mamdani 1974, Larsen 1980, Yamakawa 1989). The application of fuzzy control concepts in DEDS has not been paid much attention until recent ycars. Fuzzy linear programming has becn investigated since the early 1980s (Ernst 1982, Chanas et al. 1984), whilc the idea of fuzzy scheduling appeared in the late 1980s (Hinz and Zimmermann 1989). It seems that recent applications in DEDS have been concentrated on scheduling problems (Montazeri and Van Wassenhove 1990, Ishii et al. 1992, Grabot et al. 1994, Grabot and Geneste 1994, Custódio et al. 1994). So far no publications on fuzzy control of DEDS have been found.

Although no application of the fuzzy control concept in DEDS control has becn found, we argue that fuzzy control is an attractive altcrnative for the control of such systems becausc of the aforementioned reasons. As a new application arca for the fuzzy control concept, the authors have applied the concept to a single-machine system control problem. After a brief illustration of DEDS in Section 2, the fuzzy control concept is presented in Section 3. A descriptive model of the single-machine system and its control system is given in Section 4. Section 5 dcals with the simulation study and analysis of the fuzzy control performance in comparison with two other control strategies. Finally, conclusions and recommendations are provided in Section 6. The study should be considered as the first step in applying the fuzzy control concept to the control of DEDS.

\section{System characteristics}

The production process of a system is illustrated by the funnel model (Kettner and Bechte 1981, Wiendahl 1992) as shown in Figure 1, and can be described by the following formula (Little 1961, Kettner and Bechte 1981, Wiendahl and Nyhuis 1984):

$$
\text { mcan weighted lead time }=\frac{\text { mean work-in-process }}{\text { mean throughput }}
$$

The problem that we are interested in is how to meet the dcmands of customers while keeping a high profit for the system. One measure is to have reliable short delivery time of orders with a high system production rate. Reliable short

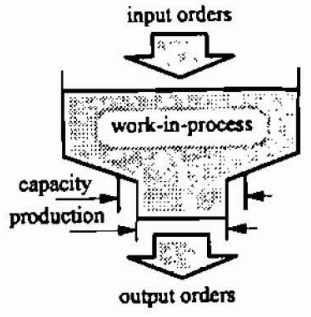

Figure 1. The funnel model.

delivery times can be ensured by reliable short lead times. The control objective is thus to obtain short mean lead times at a reasonably high rate of production (throughput). A high work-in-process generally means a high rate of production, but leads to long lead times. Low work-in-process may guarantec short lead time, but it results in a low rate of production. Obviously, these parameters have conflicting relations and a good knowledge of the three parameters, namely lead time, work-in-process and throughput, is helpful in making the compromise between the two controlled parameters.

The mean weighted lead time is determined by the ratio of the mean work-in-process to the mean throughput. A graphic representation of the relation between these three main parameters is given in Figure 2 (Wiendahl 1987, 1988). The mean lead time (mlt) and the mean throughput (tp) are given separately as a function of the mean work-in-process (wip). The tp and mlt curves representing these two functions are defined as the characteristic curves of the system.

The critical points on the idealized tp and mit curves correspond to a wip at which the system works at full capacity, whereas lead time attains its minimum value when equal to the mean operation time. Increasing wip from this point maintains the production rate constant and equal to the system capacity, but the lead time increases proportionally to the wip. The lead time will be maintained constant and equal to the operation time if wip decreases from this point, with a sharp proportional decrease in the production rate. The characteristic curves in Figure 2 are thus divided into two parts. The unshadowed part implies the machine idle or waiting for orders from time to time. The shadowed part

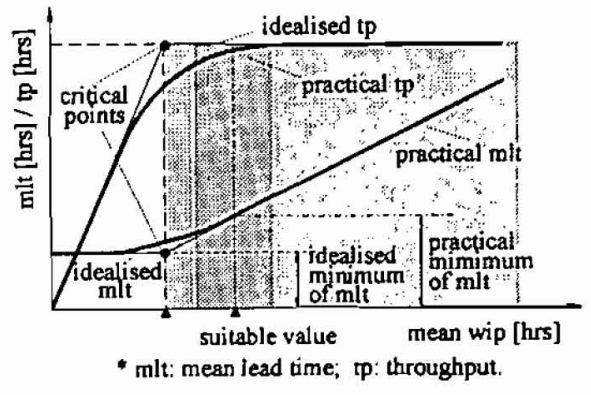

Figure 2. Characteristic curves. 


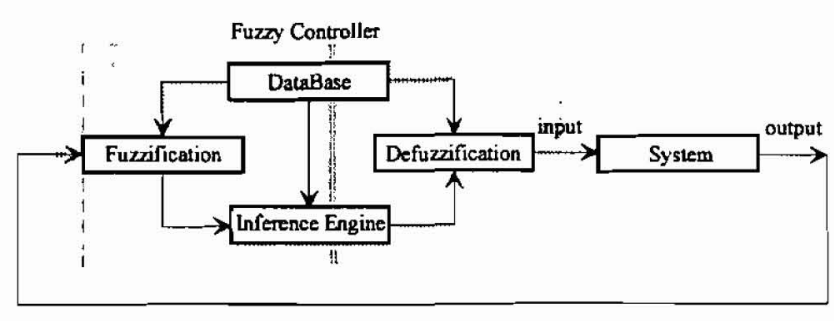

Figure 3. Fuzzy control structure.

represent the cases in which the system is always busy. The critical points are obviously the desired stable work points.

The mean throughput will become lower and the mean time will become longer for increased disturbance to the system. This means the tp curves in Figure 2 will shift down, while the mlt curves will shift up: tp and mlt can be controlled by adjusting wip. Obviously it is only interesting to apply control over the shadowed part of Figure 2. The goals of the control are to solve the conflict and to make a good compromisc between t $p$ and mlt. This goal can be achieved by kecping a proper constant wip. The tp and mlt curves can be obtained by varying wip. Idealized curves can be obtained by a few simple calculations (Section 5). The closer these curves to the idealized curves the better the control performance.

\section{Fu'zzy control}

Before we further discuss fuzzy control, a clear idea of what fuzzy set theory is should be given. A fuzzy set is an extension of a crisp set and is a class of objects with a continuum of grades of membership. An element of the universe may partly belong to such a set. Logic operations, like intersection and union, can be applied to fuzzy sets. For more information on fuzzy set theory, refer to Zadeh (1965), Zimmermann (1992) and Driankov et al. (1993).

Fuzzy control is effected by expressing experience and expertise and applying fuzzy logic to attain an action that can influence the controlled process. Fuzzy logic is a way of representing and reasoning with uncertain or inexact knowledge, i.e. linguistic knowledge, for example low work-in-process, short lead time and high throughput. It is an extended form of binary logic that endows computers with the ability to use fuzzy or linguistic concepts. The structure of a fuzzy controller is typically as shown in Figure 3.

The system input and output variables are represented symbolically in the fuzzy controller. These symbolic variables are associated with fuzzy sets and are defined as fuzzy variables. Each fuzzy set is represented by a membership function. All the relevant membership functions derived from expert knowledge are pre-stored in DataBase. The fuzzy rules, which are derived from operator experience or expert control knowledge, are expressed using the symbolic fuzzy variables. These rules are also pre-stored in DataBase.

Once the observation of a system output variable is sent to the fuzzy controller, the fuzzification element transforms the received observation into fuzzy values. These fuzzy values represent to what degree the observed value belongs to each set associated with this variable. This is called the fuzzification process. The reasoning process evaluates the rules with the fuzzy values obtained by the fuzzification process. The reasoning process is carried out by an inference engine which is the kernel element of the fuzzy controller. The Mamdani implication and inference are used to implement the reasoning process in our study. This reasoning process results in a combined fuzzy value which is used as the control signal after the defuzzification process. The defuzzification process which translates the combined fuzzy value into a crisp value is performed by the defuzzification element. Several defuzzification methods are available and the centre of gravity (COG) method is most often applied.

The control process can be illustrated in detail by means of an example: the control of a single-machine system. This is an extremely simple DEDS, but it illustrates nicely the possibility of applying fuzzy control in DEDS. The output variables of the system are the lead time and the work-in-process (wip). The deviation of the lead time from the norm (or desired) mean lead time is denoted by dlt and is equal to (lead time - norm mean lead time). The dlt and wip are the two input variable to the fuzzy controller. The control signal is the arrival rate of orders to the system which is realized by an acceptance interval. The acceptance interval (ain) is a time interval within which only one order can be accepted. The smaller the acceptance interval, the higher the arrival rate.

The dlt and wip are represented by fuzzy sets as shown in Figure $4(a)$ and (b). Each variable is associated with three fuzzy sets which are $50 \%$ overlapped with each other. The widths of all sets for one variable are equal. For simple reasons, triangular membership functions ( $\mathrm{mfs}$ ) are chosen in our application to represent all the fuzzy sets. These $\mathrm{m} f \mathrm{~s}$ are generated intuitively on the basis of the experts' knowledge for this application, but they can be easily adapted for other applications by modifying a few parameters. The ain is also associated with three fuzzy sets as illustrated in Figure 4(c).

With observation 7 for dlt (Figure 4(a)), its fuzzy value is 1 in the large set. While with observation 27 for wip (Figure $4(\mathrm{~b})$ ), the corresponding fuzzy values are 0.35 and 0.65 in the $o k$ set and the high set, respectively. The shadowed area of ain

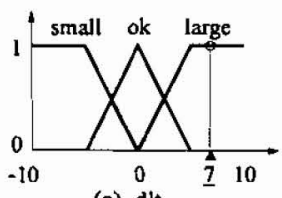

(a) $\mathrm{dlt}$

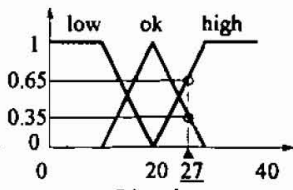

(b) wip

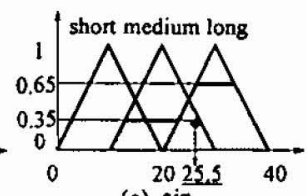

(c) ain
Figure 4. Fuzzy control process. 
Table I. The rule base for single-machine system control.

\begin{tabular}{|c|c|c|c|}
\hline \multirow[b]{2}{*}{ dlt } & \multicolumn{3}{|c|}{ WIP } \\
\hline & Low & OK & High \\
\hline $\begin{array}{l}\text { small } \\
\text { ok } \\
\text { large }\end{array}$ & $\begin{array}{c}\text { short } \\
\text { short } \\
\text { medium }\end{array}$ & $\begin{array}{l}\text { short } \\
\text { medium } \\
\text { medium }\end{array}$ & $\begin{array}{c}\text { medium } \\
\text { long } \\
\text { long }\end{array}$ \\
\hline
\end{tabular}

(Figure 4(c)) is the combined fuzzy set obtained by evaluating two relevant rules in the rule base (Table 1).

This rulc basc is a representation of the linguistic control protocol derived on basis of the experts' knowledge. In the table form of the rule base, the last row and the last column, for cxample, define one of the active rules: if dlt is large and wip is high then ain is long. Interpreting the intersection and with a minimum operation, $\min (1,0.65)$, the resulting fuzzy value for the rule antecedent is thus $0 \cdot 65$. This value will be used to limiting the fuzzy set long for ain according to Mamdani's implication (an explanation of the if-then rule). All relevant rules are evaluated separately and these individual results will then be combined by a union action follows Mamdani inference.

The centre-of-gravity defuzzification method is used here to get a crisp value from the combined fuzzy set. This crisp value, 25.5 in Figure $4(\mathrm{c})$, will be sent to the system to implement the control. Depending on the observation of the lead time and the work-in-process, more rules can be evaluated at the same time to obtain the control results. This control process will be implemented to conduct the simulation study later on.

\section{One-machine system model}

A system model is needed here to conduct control. Because of the features of DEDS, it is not possible to have a mathematical model of such a system. A descriptive model of a systcm is realized using a discrete-event simulation technique. The object-oriented language SmallTalk is used to specify and model the system. Simulation studies of the control performances are carried out on the basis of the descriptive model which is implemented on a normal personal computcr.

An industrial system is described by a collection of processes and channels. Channels realize the communication between processes. A process is called a compound process if it is represented by a collection of processes and channels. Simple processes are described by process descriptions (Rooda 1991a, b, c).

The top layer of the model is shown in Figure 5. The orders gencrated by the generator $\mathrm{G}$ are sent to the system $\mathrm{S}$. If an order cannot be accepted by $\mathrm{S}$ for further processing, it is

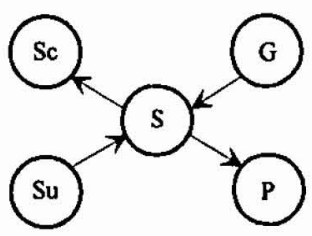

Figure 5. One-machine system model.

delivered to the sub-contractor Sc. Orders which have been processed by system $S$ are placed on the material pile $P$. The material needed for the production is supplied by the supplier Su.

$\mathrm{S}$ is a compound process that consists of two other compound processes, namely the system controller $\mathrm{C}$ and the production unit $U$ (Figure 6). $U$ sends system state information, for instance wip and lead time, to $\mathrm{C}$ via two different channels (the double arrows shown in Figure 6). This information is sent when requested by $\mathrm{C}$, and $\mathrm{C}$ is also responsible for sending the control signal to $\mathrm{U}$. Different control strategies can be employed here to perform the control function.

The compound process $U$ (Figure 7) consists of a buffer B and $a$ machine $M$. The orders accepted are stored in $B$ when waiting to be processed. $M$ can break down during processing, so that repair is necessary. This situation is modelled by introducing two statistic variables, namely the 'mean time to failure' (MTTF) and the 'mean time to repair' (MTTR). Exponential distributions are used to define these two parameters. After a period of MTTF, a failure will occur and the recovery from the failure will take MTTR. The unfinished process is continued after recovery from machine breakdown. It is known as the resume policy.

In the stable and desired situation, the input rate should be equal to the output rate and the mean lead time should be constant and equal to a desired mean lead time. It is the inevitable disturbances of the system that make the stable situation impossible, and this is why a controller is always necessary to adjust the system to overcome the disturbances.

$\mathrm{C}$ consists of three processes (Figure 8). The functions of the order acceptor A accept or reject orders and pass on accepted orders to $U$. This order acceptance can be controlled by the fuzzy controller F. This is also the place where the other different control concepts and techniques are implemented for control. Pre-calculations for the controller

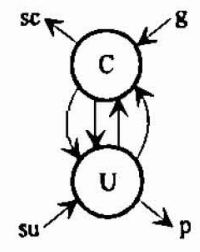

Figure 6. The system S. 


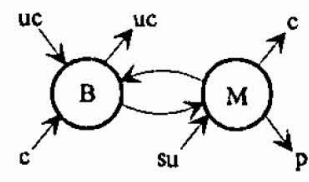

Figure 7. The production unit $U$.

and some statistical calculations are performed in the evaluator $\mathrm{E}$.

\section{Simulation with the control of the one-machine system}

Fuzzy control might be a promising technique for control of the DEDS. A series of simulation experiments have been performed with a simulation tool as described in Wortmann (1991) in combination with fuzzy control modules (Vaes 1994) to verify this. Two other control methods, P-control and LOOR-control, will be employed in this study for comparison. It is assumed that more orders are generated than the system can handle, so certain orders should be sent to the sub-contractor in order to avoid high wip, which may cause long lead times. Which orders should be sent to the sub-contractor is decided by the controller. Such a controller is capable of regulating the system under disturbances, as with machine failure.

The performance of the system without any control function can be expected to be very poor because all generated orders wait on the work floor of the system. This is because of the extremely long and unstable mean lead time due to the high work-in-process (refer to Table 2 and Figure 10(a)). The mean lead time during a simulation run is scattered across a very wide time-scale and the mean lead time of different simulation runs are quite diverse. By applying different control strategies reasonably good results can be obtained as described in the following. Each simulation study is performed over six runs, which is sufficient for a relative precision of 0.1 with $95 \%$ confidence (tested using a student's distribution). All control approaches are implemented using the feedback control structure in Figure 9.

The lead time observed from the system is compared with the norm mean lead time. Their difference, denoted by dlt, will be taken as the input variable to the p-controller. Depending on the dlt arrival rate of orders to the system can be adjusted in order to maintain a constant wip. The arrival rate adjustment is made by varying the ain as defined in

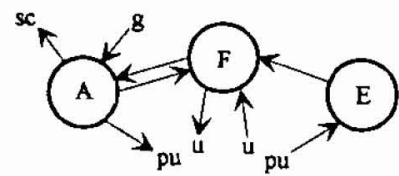

Figure 8. The system controller $\mathrm{C}$.
Table 2. No control.

\begin{tabular}{lccc}
\hline Run & m-lt & st-lt & tp \\
\hline 1 & $3942 \cdot 02$ & $2305 \cdot 67$ & 799 \\
2 & $4147 \cdot 39$ & $2325 \cdot 76$ & 797 \\
3 & $4051 \cdot 82$ & $2361 \cdot 25$ & 802 \\
4 & $3919 \cdot 60$ & $2326 \cdot 01$ & 794 \\
5 & $3974 \cdot 36$ & $2301 \cdot 61$ & 804 \\
6 & $3928 \cdot 13$ & $2250 \cdot 64$ & 795 \\
Average & $3993 \cdot 89$ & $2311 \cdot 82$ & 799 \\
\hline
\end{tabular}

Section 3. The control algorithm is: ain $=p^{*} d l l$, where $p$ is the proportional parameter which can be tuned to improve the control performance. There are many ways to tune the $p$ parameter. The $p$ value in this control is obtained in two steps: (1) dividing a wide given range of this parameter into sub-ranges; (2) choosing the middle point of the sub-range which provides the best control performance. The simulation results obtained are shown in Table 3 and Figure 10(b).

The throughput is reasonably high, while the mean lead time (mit) is much shorter and more constant than in the uncontrolled case (the smooth and stable mlt line in Figure 10(b)). The mlt is about 150 times shorter than that of the uncontrolled system and the mlt scatter is smaller. The average standard deviation of mlt is 17.00 , much smaller than the 2311.82 in the uncontrolled case. The system's performance is considerably improved.

The load-oriented order release (LOOR) control concept was developed at the Institut für Fabrikanlagen, Universität Hannover: 'The idea of load-oriented manufacturing control is to limit and balance work-in-process inventory on a level as low as possible in order to accomplish a high work-centre utilisation as well as a rapid and in-time flow of orders' (Bechte 1994). The wip is calculated periodically and the amount of work released to the system in the next period is decided according to the load limit of the system. The released work is dispatched to the system in a way which maintains the desired wip of the system. The controller is shown in Figure 9.

This LOOR concept is implemented in the discrete-event simulation environment to control the system and the simulation results are shown in Table 4 and Figure 10(c). The

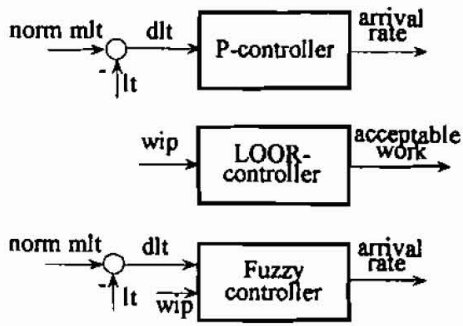

Figure 9. Three different controllers. 


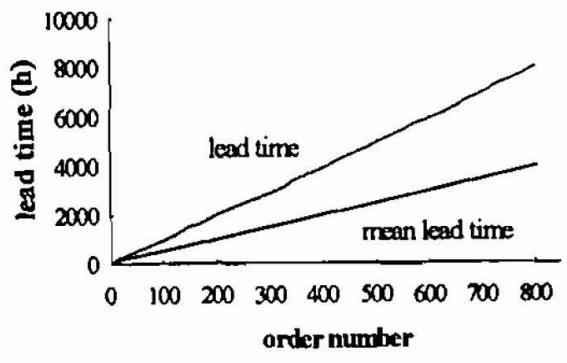

(a)

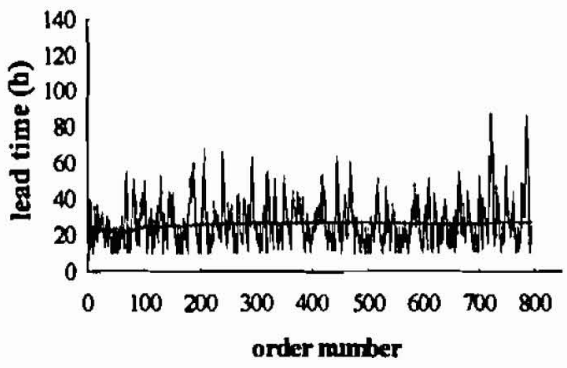

(c)

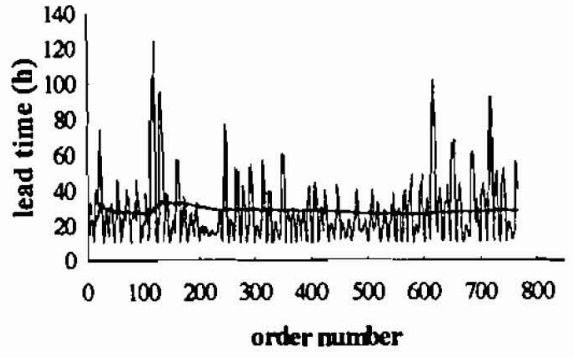

(b)

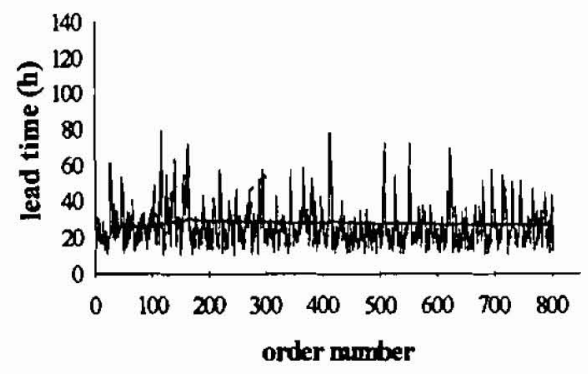

(d)
Figure 10. Lead times performance: (a) no control; (b) p-control; (c) LOOR-control; (d) fuzzy control. lead time scatter is even less than in the p-control case. The $\mathrm{mlt}$ is close to the norm mlt $(25 \mathrm{~h}$ at $20 \%$ capacity disturbance), while the throughput is higher.

The fuzzy control process described in Section 3 is implemented here to control the one-machine system. The simulation results obtained are shown in Table 5 and Figure 10(d). The small average standard deviation, 12.16 in Table 5 , implics small scatter of the mlt. The mlt is close to the norm mlt, with a reasonably high throughput.

The characteristic curves obtained by simulation are also provided for comparison with different control methods. Thesc curves arc obtained by varying the work-in-process values. The throughput as a function of the work-in-process for cach control method is shown in Figure 11. The mean lead times in rclation to work-in-process are illustrated in Figure I2.

Each point on the curves indicates one simulation run at a certain work-in-process. Each simulation runs over $10000 \mathrm{~h}$, which is long enough to neglect the transition period (about one-tenth of the simulation time). With the assumptions that each order needs $10 \mathrm{~h}$ to be processed and the mean repair time for machine failures is around one-fifth of the processing time, the mean maximum throughput (number of orders) of the system comes to 800 ( $(10000-$ $2000) / 10)$. The constant horizontal line $(t p=800)$ in Figure 11 represents the idealized tp line at $20 \%$ machine failures. If the desired mean lead time is assumed to be $25 \mathrm{~h}$, the theoretic work-in-process corresponding to this desired mean lead time should be around $20 \mathrm{~h}$, as illustrated in Figure 12. The line which connects the critical point and $(20,25)$ point and extends to the right is the idealized mit line at $20 \%$ machine failures. The theoretical mean maximum throughput can be reached with the minimum mean lead time if there is always one and only one order ( $10 \mathrm{~h}$ work) in the system (refer to Figures 11 and 12).

P-control produces the poorest results in terms of throughput and mean lead time as shown in Figures 11 and 12. The characteristic curves obtained are both far from the
Table 3. P-control.

\begin{tabular}{|c|c|c|c|}
\hline Run & m-lt & st-lt & tp \\
\hline 1 & 26.87 & $15 \cdot 30$ & 766 \\
\hline 2 & 28.69 & 18.47 & 764 \\
\hline 3 & 26.99 & 16.49 & 764 \\
\hline 4 & $27 \cdot 82$ & $17 \cdot 82$ & 767 \\
\hline 5 & $26 \cdot 42$ & $16 \cdot 45$ & 777 \\
\hline 6 & $28 \cdot 47$ & $17 \cdot 44$ & 762 \\
\hline Average & $27 \cdot 54$ & $17 \cdot 00$ & 767 \\
\hline
\end{tabular}

Table 4. LOOR-control.

\begin{tabular}{lccc}
\hline Run & m-lt & st-lt & tp \\
\hline 1 & 27.50 & 14.61 & 788 \\
2 & 27.28 & 12.60 & 797 \\
3 & $27 \cdot 15$ & 12.83 & 795 \\
4 & 27.55 & 14.91 & 792 \\
5 & 26.87 & 13.90 & 801 \\
6 & 26.94 & 14.20 & 799 \\
Average & 27.22 & 13.84 & 796 \\
\hline
\end{tabular}


Table 5. Fuzzy control.

\begin{tabular}{lccc}
\hline Run & m-lt & st-lt & tp \\
\hline 1 & $26 \cdot 56$ & $11 \cdot 63$ & 804 \\
2 & $26 \cdot 64$ & $11 \cdot 68$ & 799 \\
3 & $27 \cdot 29$ & $12 \cdot 63$ & 795 \\
4 & $26 \cdot 79$ & $12 \cdot 19$ & 803 \\
5 & $27 \cdot 04$ & $12 \cdot 80$ & 811 \\
6 & $27 \cdot 15$ & $12 \cdot 00$ & 807 \\
Average & $26 \cdot 91$ & $12 \cdot 16$ & 803 \\
\hline
\end{tabular}

idealized curves. This may be due to non-optimal tuning of the $p$ parameter. However, we should notice that it is rather time consuming to tune the $p$ parameter. Besides, because there is no mathematical model of the system available, to conceive a precise p-controller for such a system control is extremely difficult, and is not preferred for such system control,

The LOOR-control method gives very good results in terms of mean lead time and throughput as depicted in Figures 11 and 12. The characteristic curves are closer to the idealized curves than with p-control. The LOOR-control developed using many years of expert effort is a good control method. If the constraints can be relaxed by proper representation of this control method, the control performance might be more attractive.

The characteristic curves obtained by applying fuzzy control are also quite close to the idealized curves. Fuzzy control provides quite good results in terms of the compromise between mean lead time and throughput. The standard deviation of the mean lead time under fuzzy control is the smallest obtained. With the ability to represent and to reason with linguistic knowledge, fuzzy control can provide reasonably good control by employing operators' experience and experts' knowledge for DEDS system control. It will be quite interesting to combine the fuzzy control concept with other expert knowledge based control concepts, such as the LOOR control concept.

The development of a fuzzy controller is slower than that of a p-control, but once one has the membership functions, inference engine, etc., in place, it is easy to change the control strategy. Thus the application of the fuzzy control concept in a discrete industrial system control is a realistic option.

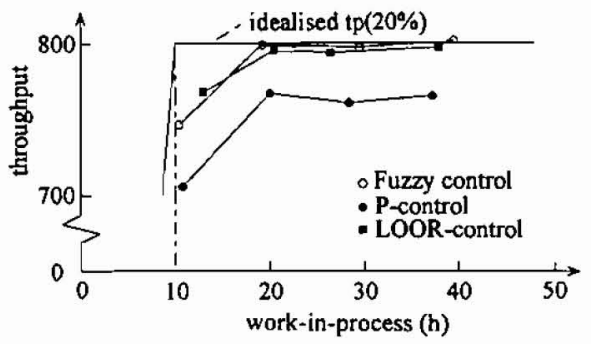

Figure 11. Throughput versus work-in-process.

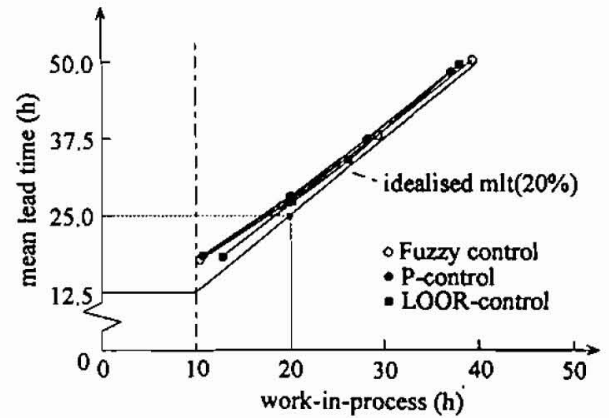

Figure 12. Mean lead time versus work-in-process.

\section{Conclusions}

A fuzzy controller can be implemented with little effort, and control is quite satisfactory with respect to the compromise between throughput and mean lead time. A good compromise between different parameters can easily be achieved by applying fuzzy control. The study shows that it is indeed a good control approach for controlling DEDS when compared to two other control concepts. It may be argued however, that this simple control system does not need to use a fuzzy control technique; however, the control of such a simple system was not our purpose. This study was undertaken to gain insight into the problem of the application of fuzzy control concepts for complex discrete industrial systems, like job shops. The results obtained lend support to the possible application of fuzzy control in job-shop systems. By properly applying experts' knowledge, for instance Wiendahl's LOOR control concept, a promising fuzzy controller can be expected. Currently, research is being undertaken to control complex job-shop systems using a fuzzy control concept in combination with a LOOR control concept.

\section{References}

BECHTE, W., 1994, Load-oriented manufacturing control just-intime production for job shops. Production Planning $\mathcal{E}^{\circ}$ Control, 5, 292-307.

Chanas, S., KolodziejczyK, W., and MachaJ, A., 1984, A fuzzy approach to the transportation problem. Fuzzy Sets and Systems, 13, 211-221.

Custodio, L. M. M., SENTieiro,J.J. S., and BisPo, C. F. G., 1994, Production planning and scheduling using a fuzzy decision system. IEEE Transactions on Robotics and Automation, 10, 160-I67.

Driankov, D., Hellendoorn, H., and Reinfrank, M., 1993, An Introduction to Fuzzy Control (Springer-Verlag, Heidelberg).

ERnst, E., 1982, Fahrplanerstellung und Umlaufdisposition im Containerschiffsverkehr (Frankfurt/M., Bern).

GRABOT, B., and Geneste, L., 1994, Dispatching rules in scheduling: a fuzzy approach. International Joumal of Production Research, 32, 903-915.

Grabot, B., Geneste, L., and Dupeux, A., 1994, Multi-heuristic scheduling: three approaches to tune compromises. Journal of Intelligent Manufacturing, 5, 303-313. 
HiNI"z, G. W., and ZimmermanN, H.J., 1989, A method to control flexible manufacturing systems. European foumal of Operations Research, 41(3), 321-334.

IsHII, H., TADA, M., and MAsudA, T., 1992, Two scheduling problems with fuzzy due-dates. Fuzzy Sets and Systems, 46, 339-347.

Keir'Th.R, H., and BkChTE, W., I98I, Neue wege der Fertigungsstcucrung mit belastungsorientierter Auftragsfreigabe. VDI-Z 123 (li), pp. 459-465, VDI-Verlag, Düsseldorf, Germany (in German).

IAARSEN, P. M., 1980, Industrial applications of fuzzy logic control. Intemational foumal of Man-Machine Studies, 12, 3-10.

L.J'I'LE, J. D. C., 1961, A proof for the queuing formula $L=\lambda * W$. Operations Research, 9, 383-387.

MAMDANI, E. H., 1974, Application of fuzzy algorithms for control of a simple dynamic plant. Proceedings IEE, 121, 1585-1588.

MONINZERL, M., and VAN WASSENhOVE, L. N., 1990, Analysis of scheduling rules for a FMS. Intemational foumal of Production Research, 28, 785-802.

ROOIA, J. E., $1991 \mathrm{a}$, Procescalculus: nieuw instrument beschrijft industriele systemen. $I^{2}$ Werktuigbouwkunde, 5, 13-15 (in Dutch).

RoOIA, J. E., 199lb, Procescalculus: systemen, modellen en formcle talen. $I^{2}$ Werktuigbouwkunde, 8, 36-39 (in Dutch).

RoODA, J. E., 1991c, Procescalculus: definities en begrippen. $I^{2}$ Werktuigbouwkunde, 8, 35-40 (in Dutch).
VAES, H.J., 1994, A package for fuzzy control in Smalltalk 80. Internal report, Eindhoven University of Technology, The Netherlands.

WiENDAHL, H.-P., and NyHUis, F., 1984, Analysis and control of manufacturing process of job shop production by a new input-output method. Proceedings of the Ist Intermational Conference on Machine Control Systems, October 23-25, Brighton, U.K., pp. 169-178.

WIENDAHL, H.-P., 1987, Belastungorientierte Fetigungssteuenung: Grundlagen Verfahrungsaufbau Realisierung (München, Germany, Carl Hanser Verlag).

WIENDAHL, H.-P., 1988, Load-orientated production control-a contribution to the logistics-orientated factory. Logistics in Mantfacturing (IFS Ltd. Kempston, UK and Springer-Verlag, Berlin, Germany), pp. 77-87.

WIENDAHL, H.P., 1992, Application of load-oriented manufacturing control in industry. Production Planning \& Control, 3, 118-129.

YAMAKAWA, T., 1989, Stabilization of an inverted pendulum by a high-speed fuzzy logic controller hardware system. Fuzzy Sels and Systems, 32, 161-180.

WORMANN, A. M., 1991, The modelling and simulation of industrial systems, PhD thesis, Eindhoven University of Technology, The Netherlands.

ZADEH, L. A., 1965, Fuzzy sets. Information and Control, 8, 338-353.

Zimmermann, H.J., 1992, Fuzzy Set Theory-And Its Applications, (Kluwer Academic, Massacbusetts, USA). 